design from the top, the exercise of granting university charter exhibits a top-down approach as well, whereby Chinese universities are required to work their charters out of a pattern/model preset by the government. In contrast, the experience of experimental colleges/schools showcases a bottom-up approach, whereby many grassroots initiatives could be identified and implemented. Compared with those top-down moves, the experimental units are more likely to tap autonomous practices into existing operations, often in a genuine and innovative way. Arguably, in the world of nature, microorganisms play a more significant role in shaping climate, than lions and elephants. In this sense, this experimentation has been ushering in a quiet revolution that might transform the climate of Chinese higher education.

Nonetheless, this view does not rule out the challenges and risks that might stand in the way of these experimental colleges/schools. From the perspective of path dependence behavior patterns of organizations, it is a challenge to keep the current innovative practices (e.g., the PI-led research groups and Chair Professor-led teaching platforms in the case of Tianjin University) from sliding back onto the old path (becoming another kind of administrative or bureaucratic mechanism). However, this is not going to happen; it is still tricky to prevent too much power from following to and concentrating in the hands of a few PIs and Chair Professors on one hand and to ensure a wide participation of the faculty in decision making on the other.

\section{Access to Higher Education: The Israeli Case}

\section{IRIS BEN-DAVID AND YAAKOV IRAM}

Iris Ben-David and Yaakov Iram teach in the School of Education at Bar-llan University, Ramat Gan, Israel. E-mail: iris.bendavidhadar@ gmail.com and Iram@biu.ac.il.

$\mathrm{T}$ he Israeli academic system is well-developed and exhibits a high level of academic achievement (e.g., high citation rate, Nobel Prize Laureates per capita and hightechnology start-ups). Israel economy is highly dependent on its academic level and its high-tech industry, which has led the state of Israel to its remarkable economic growth over the past decade. Furthermore, Israel's high academic level is perceived as an infrastructure for its very existence.

Nonetheless, along with the excellent achievement of the Israeli academia, in recent years it is facing substan- tial challenges as a result of fundamental economic, demographics, and cultural trends that are changing the social composition of Israel. These trends challenge the ability of Israel's academia to sustain its highly ranked achievement.

Economic trends burden the ability to access higher education. The knowledge-based economy indeed contributes to the economic growth, yet it has an adverse effect of growing inequality. The incremental income inequality and the rising tide in child poverty (among Israeli children currently every third child is poor) actually change the background characteristics of the potential Israeli student.

In addition, demographic trends in Israel have been reaching the point that challenges the status quo of the Israeli society. Among the first graders in the Israeli school system, more than 50 percent are either Arabs or UltraOrthodox Jewish. Demography is not the only challenge. The cultural barriers pose a further challenge. Within Israel population more than 20 percent are Ultra-Orthodox Jewish people, most of them uninterested in institutions of higher education.

Indeed, Israeli decision makers aspire to diminish the impact of these trends, by designing and enacting various policy reforms. Hitherto, political considerations of redistribution (e.g., allocating from "rich" to the "poor") hinder the achievement of an effective defacto policy.

This article focuses on trends in access and stratification within Israeli higher education. Israel serves as an interesting case given the sociocultural and ethnic diversity of its population, the majority-minority balance of power, its incremental trend in inequality, and its crucial rising percentage of child poverty.

\section{ACCESS}

The incremental trend of access to Israel's higher education institutions is reflected in the increasing percentage of students enrolled in a relevant age group in undergraduate programs, ranging from 6 percent in 2004 to 7.4 percent in 2012. As of 2014, I94,I29 students in Israel are enrolled in undergraduate programs. A less prominent trend is evident in the graduate programs, where student enrollment was I. 8 percent in 2004 and is currently similar: some 52,698 and Io,6I5 students are enrolled in graduate and PhD programs, respectively.

This incremental trend of access to Israeli higher education is more prominent among Arab students than their Jewish counterparts. Specifically, Arab students' access has increased by 53 percent (from 2.8 percent in 2004 to 4.3 percent in 20I2). The Jewish sector exhibits a more modest incremental trend of I8 percent (from 7.I percent in 2004 to 8.4 percent in 2012 ). 


\section{Stratification}

In spite of this incremental trend of access, stratification is still evident. The gap between ethnic groups, though decreasing, is still notably wide. Specifically, the gap between Jewish and Arab students enrolled in undergraduate programs was reduced from more than 2.5 -fold to less than 2-fold (between 2004 and 2012).

A gender gap does not exist within the general student population. Furthermore, according to Israel's Central Bureau of Statistics Annual Report (2013), there was a reversal in the trend among the recipients of higher degrees from universities. For example, in 1992 the gender gap of graduate students favored men-graduate: ${ }_{5} 6$ percent (44 percent, for women); and PhD: 67 percent (33 percent, for women). Indeed, two decades later (2010), the gap favored women-graduate: 56 percent (44 percent, for men); and PhD: 50 percent (50 percent, for men). At the undergraduate level the gender gap of favored women is wideningin I992: 52 percent ( 48 percent, for men); and in 2010: 57 percent (43 percent, for men). However, Arab women are less likely to acquire higher education than are Arab men or Jewish women.

Stratification already exists in lower schooling levels. The achievement distributions of Israeli students-as measured by the international examinations of the Program for International Student Assessment in 2006, 2009, and 20I2-are all characterized by an average achievement level and a wide achievement gap. In fact, Israeli high-school students exhibit the widest achievement gap among Organization for Economic Cooperation and Development (OECD) countries.

Apparently, achievement in high school (e.g., achieving a high-school matriculation certificate) is not the only gatekeeper to access to higher education. Moreover, there are numerous obstacles that nurture the stratification of Israeli higher education. In Hebrew-speaking high schools, about 70 percent of those eligible for the matriculation certificate have access to higher education. In comparison, in Arabicspeaking high schools, less than 50 percent of those eligible for the matriculation certificate have access to higher education.

Stratification in higher education can only partially be explained by low socioeconomic strata. Specifically, within those Jewish households having low socioeconomic strata, one out of three persons has access to higher education, in comparison with two out of three among Jewish households having high socioeconomic strata. However, within the Arab households, less than one out of three has access to higher education regardless of their socioeconomic strata.

\section{POLICY IM PLICATIONS}

The longitudinal examination is encouraging, since access to Israeli higher education has had an incremental trend. However, it is still stratified for ethnic minority groups and for students from low socioeconomic strata. This might challenge the fragile cohesion within Israel. The trend is for improvement-for increased access and reduced stratification-but the rate of improvement is currently too slow. Other OECD countries have higher access rates or larger improvement rates, which challenges Israel competitiveness-a highly important asset for Israel.

In fact, it is likely that any reform in higher education is doomed to be less effective, unless it is a part of a more holistic view of the education system at all levels. An equitable school finance policy is necessary. Obviously, more work is required in order to better understand the actual gatekeepers (beyond the obvious factor of socioeconomic strata). Also, although decision makers might recognize that such a reform would have a positive effect on decreasing stratification in Israeli higher education, they have to deal with the political issues of redistribution. The issues illustrated in Israel might be relevant for other multicultural countries that are facing the challenge of reducing inequality.

\section{NEW PUBLICATIONS}

Arum, Richard, and Josipa Roksa. Aspiring Adults Adrift: Tentative Transitions of College Graduates. Chicago: University of Chicago Press, 2014. 239 pp. \$18 (pb). ISBN 978-0226-19728-9. Web site: www.press.uchicago. edu.

The authors of an earlier book, Academically Adrift-an influential critique of the impact of American undergraduate education-focus in this volume on the final years of undergraduate study and the transition to work. Using data from the Collegiate Learning Assessment, the authors find that graduates have a difficult time transitioning to work and establishing stable relationships, although they are optimistic about the future. The data and focus of this book are on the United States.

Bassett, Roberta Malee, and Alma Maldonado-Maldonado, eds. Organiamos Internationales y Políticas en Educación Superior:
Pensando globalmente, actuando localmente. México, DF: ANUIES, 2014. 423 pp. (pb). ISBN 978-607-451-089-8.

This book is an analytical perspective concerning how international and regional organizations relate to higher education-globally and in individual countries. Chapters focus on key international groups such as UNES$\mathrm{CO}$, the World Bank, and others as well as regional associations in Africa, Latin America, and elsewhere. 